\title{
A Peep into the Plant miRNA World
}

\author{
Neeti Sanan Mishra* and Sunil Kumar Mukherjee
}

International Center for Genetic Engineering and Biotechnology, New Delhi, India

\begin{abstract}
RNAs constitute a major class of the small regulatory molecules that are involved in regulating the intrinsic normal growth of cells and development of organisms as well as in maintaining the integrity of genomes. The plant miRNA research gained momentum, 2002 onwards with identification of new miRNA molecules and their targets. This was accompanied by the discovery of plant homologs of proteins involved in miRNA biogenesis, including a new member SERRATE. The identification of several diverging and converging functions of miRNAs indicate that they play versatile roles in regulating cell differentiation and tissue development. This article provides an update on the conservation and identification of plant miRNAs. The classical miRNA biogenesis pathway and the associated proteins are discussed along with the emerging concept on the processing of miRNA-encoding introns (mirtrons). It also contains a concise account of plant miRNA targets and functions with focus on the recent successful attempt on engineering synthetic miRNAs to study gene function as well as to impart virus resistance in plants.
\end{abstract}

Keywords: microRNAs, plant, biogenesis, mirtrons, functions.

\section{INTRODUCTION}

A growing body of evidence suggests that 19-24 nt long non-coding RNA play crucial roles as regulators of gene expression in eukaryotes. The regulatory role for RNA was discovered during understanding of the post-transcriptional gene silencing (PTGS) in plants. Silencing was triggered by expression of a transgene homologous to an endogenous gene, which resulted in the formation of long doublestranded RNA (dsRNA) (Fire Nature 1998) [1] (Hamilton Science 1999) [2] (Vance Science 2001) [3]. The dsRNA trigger was cleaved into 22-25 nt RNAs (Bernstein Nature 2001) [4] which act as guides to target homologous mRNA sequences for destruction (Elbashir Gen Dev 2001) [5] (Hammond FEBS Lett 2005) [6]. RNAi in mammals and quelling of Neurospora are related pathways that require production of regulatory small RNAs. These regulatory molecules offer cellular protection against stressful environment and parasitic nucleic acid sequences. They carry out epigenetic as well as genetic alterations on one hand and govern organism architecture and development on other (Agrawal MMBR 2003) [7]. A major class of the small regulatory molecules, known as microRNAs (miRNAs) is involved in regulating the normal growth of cells and development of organisms as well as in maintaining the integrity of genomes.

\section{HISTORY}

The discovery of miRNAs was marked by the identification of lin-4 and let-7, as post-transcriptional regulators of the heterochronic gene, lin-14, involved in controlling developmental timing and cellular differentiation in Caenorhabditis elegans (Lee Science 2001) [8] (Reinhart Nature 2000) [9]. The sequence and developmental expression pattern of let-7 is highly conserved in a wide range of animals, suggesting its important role in regulating biologi-

*Address correspondence to this author at the International Center for Genetic Engineering and Biotechnology, Aruna Asaf Ali Marg, New Delhi, India; E-mail: neeti@icgeb.res.in cal processes (Pasquinelli Nature 2000) [10]. These findings initiated the discovery of miRNA and other small RNAs in different organisms. Currently, around 5,071 miRNA sequences from primates, rodents, birds, fish, worms, flies, plants and viruses have been identified and deposited in publicly available, miRBase Sequence database-release 10.0 (Griffiths-Jones NAR 2006) [11]. The identification of miRNAs in plants was reported in 2002 simultaneously by different groups (Llave Science 2002) [12] (Reinhart Gen Dev 2002) [13] (Park Curr Biol 2002) [14]. Since then there has been an exponential increase in the identification of miRNAs as well as in understanding the significance of their roles in biological processes.

\section{SEQUENCE CONSERVATION}

miRNAs constitute a major class of small non-coding RNAs. They are transcribed as long primary transcripts (primiRNA) that are first trimmed into the hairpin intermediates called precursor-miRNAs (pre-miRNAs), which are subsequently cleaved into mature miRNAs. Several miRNAs are conserved across animal and plant kingdom (Pasquinelli Nature 2000) [10].

Experimental and computational analysis indicates that many plant miRNAs and their targets are conserved between monocot (rice) and dicot (Arabidopsis) species (Bonnet PNAS 2004) [15] (Wang Gen Biol 2004) [16] (Wang NAR 2004) [17]. This indicates that miRNAs arose early in eukaryotic evolution, before the divergence of monocots and dicots. Unlike in animals, only the mature miRNAs are conserved in plants instead of pre-miRNAs (Bartel Cell 2004) [18]. However, two recent reports have shown different evolutionary patterns for plant miRNA precursors as well. Bartel's group (Reinhardt Gen Dev 2002) [13] reported that for many miRNA families only the mature miRNA and the miRNA* was significantly conserved between Arabidopsis and rice. In contrast, Weigel's group (Palatnik Dev Cell 2007) [19] found extensive conservation of the miR159 and miR319 precursors between dicots and monocots. 
The conservation of miRNA and their precursors across species implies that miRNAs might have played roles during the origins and evolution of multicellular life including both plant and animal (Reinhart Gen Dev 2002) [13] (Floyd Nature 2004) [20]. In fact, the recent discovery of miRNA in single-celled organism like Chlamydomonas reinhardtii pushes the limit of antiquity of miRNA machinery quiet far down the evolution (Molnar Nature 2007) [21]. It is not unlikely that some primitive form of RNAi machinery evolved even in the prokaryotes (Barrangou Science 2007) [22].

\section{IDENTIFICATION}

Plant miRNAs have been identified using one of the three primary strategies. A first approach has been the identification of miRNAs through genetic screens. This approach led to the first identification of small RNAs in animals (Palatnik Nature 2003) [23]. The second relies on the direct cloning of small RNAs. Several labs have prepared small RNA libraries from Arabidopsis and a few including our laboratory, from rice involving different tissues and physiological conditions (Reinhart Gen Dev 2002) [13] (Sunkar Plant Cell 2004) [24] (Sanan-Mishra, unpublished). A third approach involves use of computational algorithms based on the extensive conservation of the miRNAs during evolution. $20 \mathrm{nt}$ stretches, that are conserved between Arabidopsis and rice, having sur- rounding sequences that are able to form fold-back structures have allowed the identification of several new miRNAs and the postulation of many others (Jones-Rhoades Mol Cell 2004) [25] (Adai Gen Res 2005) [26].

To date, more than 1200 miRNAs have been identified with cloning methods or computational approaches from a variety of plants. Around 500 miRNA genes in Arabidopsis, rice and maize had been identified and found to be clustered in $\sim 45$ families. Plant miRNAs are usually encoded by small gene families of up to 14 members. A miRNA family usually includes several mature miRNAs of identical or nearly identical sequence. In general, at least one member of each family has been validated experimentally, while the others have often been obtained as bioinformatic predictions based on sequence similarity of the miRNA and the ability of the surrounding region to adopt a fold-back structure (Dezulian Bioinfo 2006) [27]. Further analysis has led to cloning and/or prediction of more than 200 members of the 43 miRNA families in the genomes of maize (Zhang FEBS Lett 2006) [28], Sorghum (Mica JEB 2006) [29], Medicago (Zhang Cell Res 2005) [30], Poplar (Lu Plant Cell 2005) [31], Brassica (Xie FEBS Lett 2007) [32], Wheat (Yao Gen Biol 2007) [33], Tomato (Pilcher Planta 2007) [34] and Cotton (Zhang Gene 2007) [35].

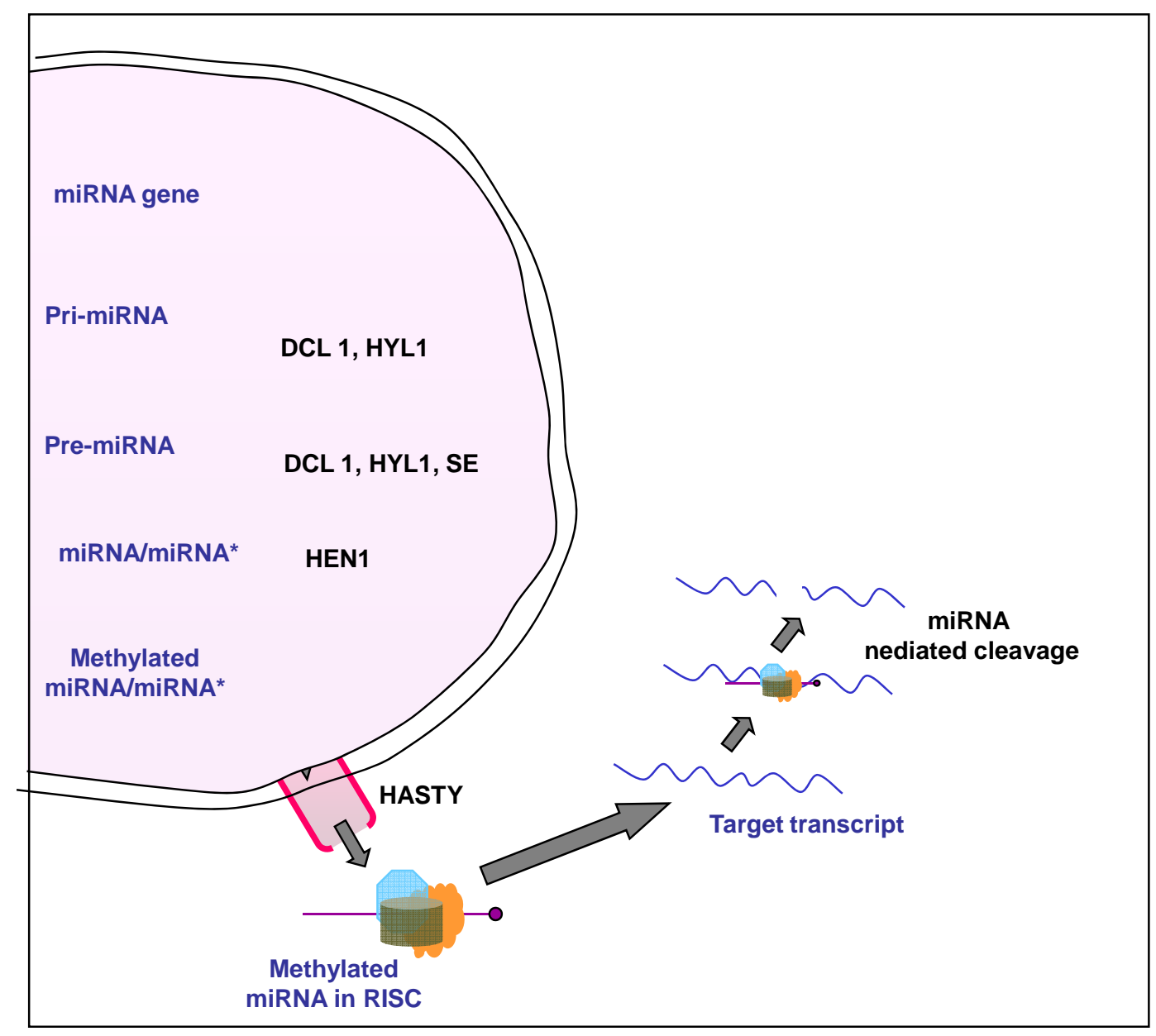

Fig. (1). Model for miRNA biogenesis and action in plants: Transcription of miR loci generates a pri-miRNA that is processed by DCL1 and possibly other proteins to yield the fold-back precursor pre-miRNA. The pre-miRNA is processed further by where DCL1, HYL1 and SE to form a miRNA-miRNA* imperfect duplex. The two strands of the duplex are methylated by HEN1 and then transported out of the nucleus in a HST dependent manner. In the cytoplasm the miRNA strand is loaded into RISC, which is then guided to the target mRNA. 
Some of these are highly evolutionarily conserved with only a few nucleotide changes among a wide variety of plant species (Zhang Cell Res 2005) [30]. Conserved miRNAs are considered to play important roles in basic organogenesis or signal transduction, while non-conserved miRNAs may play more specific roles in different tissues or plant species. In fact Carrington et al. (Allen Nat Genet 2004) [36] postulated that, the non-conserved pool may contain new miRNAs that are "born" anywhere within the plant genome from inverted duplications. Those, which are advantageous to the plant, get incorporated into the regulatory networks while others "die" i.e. are lost during evolution (Fahlgren PLoS One 2007) [37].

\section{BIOGENESIS: CLASSICAL AND MIRTRONS}

The mature miRNAs are typically derived by transcription of a large $(\sim 1 \mathrm{~kb})$ pri-miRNA from a segment of the genome that is distinct from predicted protein-coding regions. This step is typically RNA polymerase II dependent and may include splicing. The mature pri-miRNA transcripts are capped, poly-adenylated and have the potential to form highly folded structures (Kim NRMCB 2005) [38]. From this transcript arise the 70-100 nt long pre-miRNA. Mature miRNAs are processed from the imperfect duplex region of such pre-miRNA transcripts. The region of the precursor that pairs to the miRNA is called miRNA*. Experimental evidence indicates that the structure rather than the sequence of the pre-miRNA directs their correct processing (Bartel Cell 2004) [18] (Kim NRMCB 2005) [38]. In animals a primiRNA can contain several different pre-miRNAs, but in plants each transcript usually contains a single pre-miRNA. The function, if any, of the larger transcripts is currently unknown.

In animals, the pri-miRNA is processed in the nucleus into hairpin pre-miRNA by the double-strand specific ribonuclease III (RNase III) enzyme, DROSHA. The premiRNA is transported to the cytoplasm via EXPORTIN-5 (EXP-5), a transportin-5 dependent mechanism (Yi Gen Dev 2003) [39] (Lund Science 2004) [40]. It is then digested by a second, double-strand specific RNAse III enzyme, called DICER. The resulting 19-24 nt miRNA is bound by a complex that is similar to the RNA-Induced Silencing Complex (RISC) that participates in repressing the target transcript resulting in reduced expression of the corresponding gene. The plant machinery is different in that, both the pri- and pre- miRNA is processed in the nucleus by the dsRNAspecific RNAse III enzymes, DICER LIKE 1 (DCL1) to release the mature miRNA (Reinhart Gen Dev 2002) [13]. The miRNA:miRNA* duplex is then transported to the cytoplasm by EXP-5 homolog, HASTY (Bollman Dev 2003) [41] where it is incorporated into RISC to be guided to the target mRNA (Fig. 1).

Recently Bartel's group (Ruby Nature 2007) [42] showed that a special class of miRNA precursors is processed by a distinct, splicing-dependent but DROSHA-independent pathway. These originate from specific $\sim 60 \mathrm{nt}$ long introns and have been named "mirtrons". These introns fold into structures similar to pre-miRNA which favours recognition and processing by the miRNA machinery. Lai and coworkers (Okamura Cell 2007) [43] showed that EXP-5 is involved in the transfer of mirtrons to the cytoplasm. Both groups have demonstrated that the products of mirtrons are able to repress the target genes in various tissues and developmental stages. They have been so far reported only in Drosophila and C. elegans, but they may also be present in higher animal and plants. These findings also raise the possibility of existence of other varieties of intronic miRNAs that may be produced by specific nucleases in a DROSHAindependent manner (Ruby Nature 2007) [42]. The possibility of large sized introns to contain mirtrons suggests that miRNAs could have emerged through this pathway (utilizing splicing) before the advent of DROSHA.

\section{PROTEINS INVOLVED IN THE PATHWAY}

The production of different small RNAs requires a conserved set of proteins including DICER, ARGONAUTE (Fagard PNAS 2000) [44], the RNA-directed RNA polymerase SDE1/SGS2, which may amplify dsRNA used as a trigger for silencing (Mourrain Genet Eng 2000) [45], and the RNA helicase SDE3 (Dalmay EMBOJ 2001) [46].

DICER was originally identified as a nuclease involved in the siRNA generation during RNAi pathway of animals (Bernstein Nature 2001) [4]. In C. elegans, the same Dicer is utilized for miRNA biogenesis as well. However in Drosophila there are two Dicers and Dicer-1 is associated with miRNA biogenesis (Lee Cell 2004) [47]. It has an Nterminal helicase and two tandem C-terminal RNAse III domains (Ketting Gen Dev 2001) [48]. Recently Dicer1 has been also found to be involved in the processing of mirtrons into mature miRNAs (Ruby Nature 2007) [42]. In Arabidopsis, there are four DCL genes and each encodes a protein containing PAZ (PIWI/AGO1/ZWILLE) domain, a DExHbox RNA helicase, two RNAse III domains and at least one dsRNA-binding domain (except for DCL3). DCL1 is involved in processing of both the pri- and pre-miRNA, DCL2 is required for the viral siRNA while DCL3 and 4 have role in rasiRNA and tasiRNA production, respectively (Finnegan Curr Biol 2003) [49], (Xie PLoS Biol 2004) [50]. A mutation in Arabidopsis Dicer homolog, carpel factory (caf) causes substantially reduced accumulation of plant miRNAs resulting in delayed vegetative to floral transition (Park Curr Biol 2002) [14] and over-proliferation of the floral meristem (Jacobsen Dev 1999) [51].

DCL acts along with HUA ENHANCER1 (HEN1) which has two dsRNA-binding domains and a nuclear localization signal (Boutet Curr Biol 2003) [52]. HEN1 was originally isolated as an enhancer of hual, a regulator of floral organ identity, but is also allelic to the inflorescence mutant corymbosa-2 (Suzuki PCP 2002) [53]. It is involved in methylating the terminal sugar residues of miRNA to enhance the stability of miRNA (Chen FEBS Lett 2005) [54]. Unlike DCL1, HEN1 is also required for PTGS.

HASTY, an exportin 5 homolog, is involved in transporting miRNA:miRNA* duplex from the nucleus to the cytoplasm in Arabidopsis (Park PNAS 2005) [55]. Bollman and colleagues (Bollman Dev 2003) [41] demonstrated that lossof-function of hst gene caused many pleiotropic phenotypes, including disrupting leaf shape, flower morphology, reducing fertility, accelerating vegetative phase change and disrupting phyllotaxis of the inflorescence.

HYPONASTIC LEAVES1 (HYL1) is the plant homolog of R2D2 (Han PNAS 2004) [56] that acts along with DCL1 to regulate the first step of pri-miRNA processing. hyll affects leaf development, apical dominance and hor- 
mone sensitivity. It exhibits hyper-sensitivity to abscisic acid and hypo-sensitivity to cytokinin and auxin (Lu Plant Cell 2000) [57], (Vazquez Mol Cell 2004) [58]. Complete loss of HEN1 and HYL1 function causes phenotypes that are much less severe than those of agol or $d c l l$ mutants, indicating that HEN1 and HYL1 are redundant with other genes for miRNA biogenesis and function.

Recently it was shown that the Serrate (se) mutant exhibits developmental abnormalities similar with hyll mutant (Yang Plant J 2006) [59], indicating that SE plays a general role in miRNA processing. It was demonstrated that SE is localized in the nucleus and interacts physically with HYL1. Thereby suggesting that SE acts with DCL1 in processing pri-miRNAs before HEN1 (Yang Plant J 2006) [59].

ARGONAUTE (AGO) is the slicer component of RISC and is required for miRNA accumulation and PTGS. Mutations in AGO family proteins cause miRNA processing defects, leading to disruption of axillary shoot meristem formation and leaf development (Bohmert EMBO J 1998) [60], (Vaucheret Gen Dev 2004) [61], (Kidner Dev Biol 2005) [62]. AGO family members have a PAZ as well as a PIWI domain. PAZ domain may allow interaction with Dicer and other proteins and is also believed to help align miRNA with its target (Cerutti TBS 2000) [63]. The structure of PIWI domain is related to $\mathrm{RNaseH}$ and is believed to be involved in target cleavage (Cerutti TBS 2000) [63], (Song Science 2004) [64]. Ten ago-like genes are found in Arabidopsis, with even more in rice indicating redundancy in their functions. Both AGO1 and 4 are involved in silencing transposons and repeats but ZIPPY/AGO7 appears to have effects only on development (Zilberman Gen Biol 2004) [65], (Lippman PLoS Biol 2003) [66].

\section{TARGETS AND FUNCTION}

miRNAs regulate gene expression by targeting RISC to complementary sequences on the target mRNA. In animals, this causes inhibition or repression of translation machinery. Animal miRNAs can recognize partially complementary target sites. Usually multiple sites are found in the 3' untranslated region ( $3^{\prime}$ UTR) of target mRNAs. In plants, the miRNAs mark target transcripts for cleavage and seem to have a role in 'clearing out' transcripts to bring about rapid changes in the cell's fate (Bartel Cell 2004) [18]. Each target transcript has a single miRNA site that can exist anywhere along the mRNA and perfect complementarity to this site is an essential requirement (Mallory EMBO J 2004) [67].

The abundance of plant miRNA genes, their intriguing expression patterns in different tissues or in different stages of development imply that, as a class, miRNAs play versatile roles in regulating cell differentiation and tissue development. As many as 12 miRNA families regulate plant development by restricting accumulation of transcripts encoding crucial transcription factors (Rhoades Cell 2002) [68], (Bartel Cell 2004) [18], (Mallory Curr Biol 2004) [69]. In addition, some miRNAs have been found to regulate specialized processes like biosynthesis of cell wall metabolites (Lu Plant Cell 2005) [31] or cotton fiber development (Zhang Cell Res 2005) [30]. Recently we have identified some novel miRNA from rice that are predicted to target a wide range of nonDNA binding transcripts from receptor kinases to essential enzymes (Sanan-Mishra, unpublished). This indicates an extended network of the miRNA in regulating the different aspects plant morphology and development (Fig. 2).

The involvement of miRNAs in regulating various aspects of shoot morphogenesis from meristem establishment and maintenance to leaf development including abaxialadaxial polarity, organ boundaries, shape and complexity is well documented (Palatnik Nature 2003) [23], (Zhong Plant Cell Physiol 2004) [70], (Laufs Dev 2004) [71], (Kim Plant J 2005) [72] (Ori Nat Genet 2007) [73]. miRNA regulate pattern and development of leaves by targeting two classes of transcription factor genes (HD-ZIP and TCP). The intricacy of this regulation is represented in Fig. (2).

In both monocots and dicots, regulation by miR165/miR166 is required for organ axis specification, vascular development and meristem function by controlling expression of the class-III homeodomain leucine zipper (HD-ZIP) transcription factors (Bowman Bioessays 2004) [74]. In Arabidopsis, Phabulosa, Phavoluta and Revoluta are targeted by mir165/mir166 (Mallory EMBO J 2004) [67], (Zhong Plant Cell Physiol 2004) [70]. Juarez et al. (Juarez Nature 2004) [75] found that miR166 directly cleaves mRNA of rolled leaf 1, a homologue of the Arabidopsis HDZIP genes to alter leaf polarity in maize. They also observed that miR166 may be a mobile signal in leaf development. mir159/JAW also controls cell division during leaf development in Arabidopsis by targeting a subset of TCP genes. In Antirrhinum, the expression of Cincinnata, a TCP gene, marks the advancing boundary of cell division arrest (Nath Science 2003) [76]. Similarly mir319 was found to control leaf complexity in tomato by regulating levels of a TCP homolog, LANCEOLATE (Ori Nat Genet 2007) [73].

At-miR164 regulates meristem development and aerial organ boundaries by controlling the expression of CupShaped Cotyledons (CUC-1, CUC-2) and Shoot meristemless1 (STM1) (Aida Dev 1999) [77] (Laufs Dev 2004) [71]. CUC1 and CUC2 are two important transcription factors of the NAM/ATAF/CUC (NAC)-domain transcription factor family found only in plants (Riechmann Science 2000) [78]. They play important roles in both embryogenic and floral development (Aida Dev 1999) [77], (Hibara Plant Cell 2006) [79].

miRNAs also regulate the vegetative to reproductive phase transition (Achard Dev 2004) [80], (Lauter PNAS 2005) [81] and floral organ identity (Aukerman Plant Cell 2003) [82], (Chen Science 2004) [83]. miR156 is upregulated upon flowering induction and is required for the downregulation of the SQUAMOSA PROMOTER BINDING LIKE (SPL) family members which suppress flowering in Arabidopsis. Over-expression of miR156 affects phase transition from vegetative growth to reproductive growth, including the quick initiation of rosette leaves, a severe decrease in apical dominance, and a moderate delay in flowering (Wu Dev 2006) [84]. miR172 is required for the regulation of AP2 and AP2-like proteins (TARGET OF EAT 1, TOE1), which are required for flowering and floral organ identity. Over-expression of miR172 inhibited the translation of the AP2 gene and TOE1 genes resulting in early flowering and disrupting the specification of floral organ identity similar to loss-of-function ap2 mutants (Aukerman Plant Cell 2003) [82], (Chen Science 2004) [83]. In maize, the 


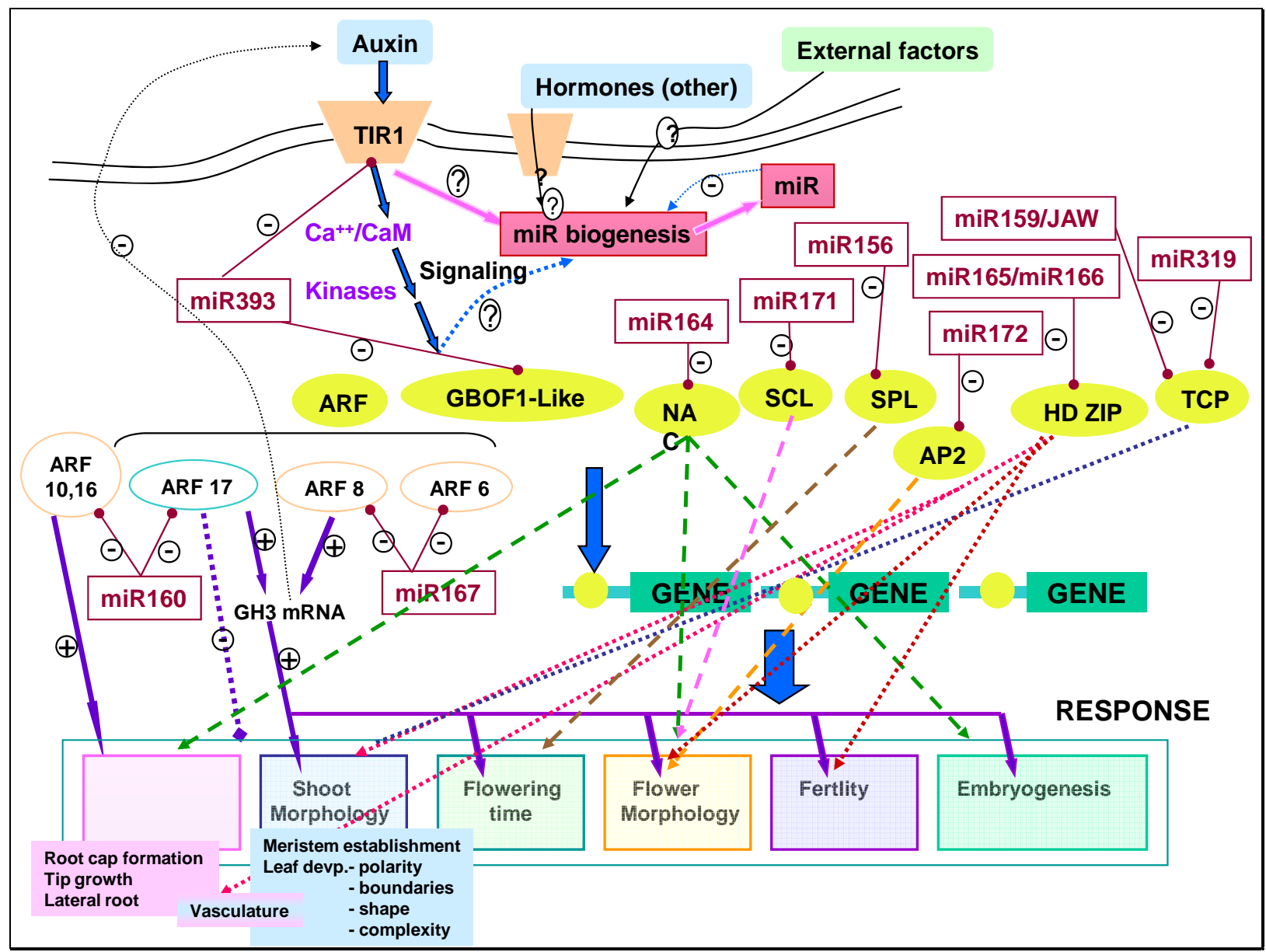

Fig. (2). A model to represent the networks in regulation of plant development in response to phytohormones and external environment: The basic scheme shows that perception of hormonal or environmental signals initiates a signaling cascade that culminates in the activation of transcription factors (yellow circles). These in turn modulate a number of downstream genes to regulate specific plant responses. The transcription factors are also regulated by different miRs (open red box). The Arabidopsis miRNAs and their targets are shown by solid lines. The regulation of miRNA biogenesis by hormones and possibly by the environmental cues may add to the complexity of the regulatory network.

inhibition of AP2-like gene, glossy15 by miR172 regulates transition from vegetative growth to reproductive growth (Lauter PNAS 2005) [81]. Llave et al. (Llave Science 2002) [12] reported that miR171 exhibits inflorescence and flower specific expression pattern, indicating its role in floral development. miR171 targets three SCARECROW LIKE (SCL) transcription factor genes, SCL6-II, SCL6-III, and SCL6-IV, in Arabidopsis and 4 in rice (Llave Science 2002) [12] Fhere are several reports on the control of root initiation by miRNAs (Mallory Curr Biol 2004) [69], (Laufs Dev 2004) [71], (Guo Plant Cell 2005) [85]. Over-expression of At-miR164 (implicated in controlling organogenesis) resulted in the fusion of vegetative and floral organs, unbalanced floral organ numbers, and reduced lateral root emergence (Mallory Curr Biol 2004) [69], (Laufs Dev 2004) [71]. At-miR164 was found to regulate expression of CUC2 and NAC1 (Guo Plant Cell 2005) [85]. NAC1 (like other members of the Arabidopsis NAC domain gene family) is an auxin responsive gene that controls lateral root growth by regulating TRANSPORT INHIBITOR RESPONSE 1 (TIR1) (Xie Gen Dev 2000) [86].

miRNAs regulate vascular development as well (Floyd Nature 2004) [20], (Kim Plant J 2005) [72]. As mentioned above miR166 controls expression of the HD-ZIP transcription factors. ATHB15, which is one such target of miR166a, is predominantly expressed in vascular tissues, suggesting that it may play some role in vascular development (OhashiIto Plant Cell Physiol 2003) [87]. Over-expression of miR166a resulted in decreasing ATHB15 mRNA levels and caused altered vascular system by accelerating vascular cell differentiation from cambial/procambial cells (Kim Plant $\mathbf{J}$ 2005) [72].

miRNAs have been found to regulate key components of hormone signaling pathways, hormone homeostasis and several plant responses to hormones (Jones-Rhoades Mol Cell 2004) [25], (Sorin Plant Cell 2005) [88]. The regulation of auxin signaling is well documented and found to be conserved among rice, Arabidopsis, Poplar, Medicago and Lotus. miRNAs target the transcription factor family, auxin response factor (ARF) which has at least 23 members in Arabidopsis (Guo Plant Cell 2005) [85], (Mallory Plant Cell 2005) [89]. miR160 targets ARF10, ARF16 and ARF17 while miR167 targets ARF6 and ARF8 (Hagen PMB 2002) [90], (Weijers COPB 2004) [91]. Bartel's group demonstrated that disrupting miR160 function led to severe developmental defects (Mallory Plant Cell 2005) [89]. As men- 
tioned earlier, miR164 blocks auxin signals for lateral root formation by regulating NAC1 expression, which in turn controls the TIR1 that assigns the Auxin (IAA) proteins to the E3 ubiquitination pathway for destruction (Xie Gen Dev 2000) [86]. miR393 also regulates auxin signaling by targeting transcripts of TIR1 and three closely related F-box proteins (Sunkar Plant Cell 2004) [24], (Jones-Rhoades Mol Cell 2004) [25].

Gibberellic acid (GA) up-regulates miR159 to modulate flowering time and anther development. miR159 targets the GAMYB transcript, a positive regulator of LEAFY, which is an important factor in floral development (Gocal Plant Physiol 2001) [92]. Over-expression of miR159 resulted in decreased LEAFY mRNAs, delayed flowering time, and altered floral development (Achard Dev 2004) [80], (Kaneko Plant Cell 2004) [93]. Zhang et al. (Zhang Cell Res 2005) [30] found that several plant miRNAs (miR159, miR160, miR164, and miR167) were obtained from tissues induced by abscisic acid (ABA), GA, jasmonic acid (JA), salicylic acid (SA), and other phytohormones.

Moreover, the miRNAs are involved in modulating various environmental stress responses, such as oxidative, mineralnutrient-, dehydration- and mechanical-stress. The role of mir399 and mir395 in regulating phosphate and sulphate ion homeostasis is well documented (Chiou Plant Cell Environ 2007) [94]. Several miRNAs like mir319, mir402, have been found to be upregulated in response to abiotic stresses like salinity, cold (Sunkar Plant Cell 2004) [24], drought (Zhao BBRC 2007) [95], and UV light (Zhou Mol Sys Biol 2007) [96]. Indirect evidence is provided by the fact that mir159 expression is upregulated in response to stress hormone ABA (Reyes Plant J 2007) [97], (Sunkar Plant Cell 2004) [24]. Similarly we have cloned around 10 miRNA sequences from rice that are induced in response to salt stress (Sanan-Mishra, unpublished). Lu et al. (Lu Plant Cell 2005) [31] identified 48 miRNA sequences from the Populus genome that target developmental-specific, mechanical stressed-induced and defense-related genes.

miRNAs also play an important role in plant defense responses to pathogen attack. Pathogen infection is an important biological factor that extensively affects plant growth and development (Gurr Trends Biotech 2005) [98]. Growing evidence indicates that miRNAs are key players in pathways to resist plant pathogens; including virus-induced gene silencing. Recently we have identified several miRNA in rice that are up-regulated in response to Tungro virus infection (Sanan-Mishra, unpublished). Viral suppressors of gene silencing like HC-Pro, p19, p21, and p69 are important pathogenicity factors that help in disease manifestation and various developmental abnormalities in infected plants (Chapman Gen Dev 2004) [99]. Several studies have shown that these suppressors are involved in the regulation of miRNA activities like HC-Pro interferes with miR171 activity, to cause related developmental defects (Chapman Gen Dev 2004) [99], (Kasschau Dev Cell 2003) [100]. One possible mechanism is that these suppressors inhibit the formation and/or activity of miRNA-containing RISC complex and result in failure of PTGS in infected plants (Kasschau Dev Cell 2003) [100] (Chapman Gen Dev 2004) [99]. The suppressors like, p69, encoded by turnip yellow mosaic virus
(TYMV), enhance the miRNA-guided cleavage of host mRNAs by increasing the transcription levels of Dicer miRNAs (Chen Science 2004) [101].

The plant miRNAs also function in feedback regulation in small RNA pathway and in directing some siRNAs biogenesis. To date, at least five miRNAs (miR162, miR168, miR173, miR390, and miR398) are known to regulate miRNA biogenesis or function Both DCL1 and AGO1 are themselves regulated by miR162 and miR168, respectively (Xie Curr Biol. 2003) [102], (Vazquez Mol Cell 2004) [58]. These miRNAs accumulate in $d c l l$ and agol mutants, indicating that DCL1 and AGO1 are regulated by feedback control. miRNA-resistant AGO1 confers vegetative phenotypes, whereas very strong agol-3 mutants accumulate lower than wild type levels of some miRNAs and higher levels of most targets (Xie Curr Biol. 2003) [102]. miR173 guides in phase processing of four ta-siRNA primary transcripts, whereas miR390 guides in-phase processing of trans-acting siRNA3 (TAS3) primary transcripts. Based on these findings it was proposed that miRNA directs the initiation of ta-siRNA biogenesis (Allen Cell 2005) [103].

\section{ENGINEERING MIRNAS}

Precursors are quite uniform in length among animal miRNAs $(\sim 70 \mathrm{nt})$, but are variable in plants (ranging from $50-500 \mathrm{nt})$. It is the position of the miRNA sequence along the precursor and not the sequence of the miRNA itself that directs the appropriate miRNA processing. The fold back structures of the pre-miRNA are the key to efficient processing of miRNA. This led to the idea that synthetic or artificial miRNAs (amiRNAs) may be designed to suppress expression of specific genes to study gene function (Zhang FEBS Lett 2006) [28]. Recently two individual laboratories designed and showed the functionality of the amiRNAs in different plant species (Alvarez Plant Cell 2006) [104] (Schwab Plant Cell 2006) [105]. Custom-made amiRNAs introduced into Arabidopsis-based endogenous pre-miRNA backbones were able to target genes that are not naturally regulated by miRNA (Alvarez Plant Cell 2006) [104] (Schwab Plant Cell 2006) [105]. The amiRNAs were highly expressed in Arabidopsis thaliana and could effectively down regulate the predicted targets (Schwab Plant Cell 2006) [105]. Both groups also found that amiRNAs were expressed in an inducible and/or tissue-specific manner. The synthetic pre-miRNAs were processed effectively in tomato and tobacco to produce phenocopies of multiple mutant combinations of the target genes. This suggests that engineered miRNAs could be widely used to knock down several related, but not identical, target genes simultaneously in a range of organisms.

Recently Arabidopsis miR159 precursor was engineered to express amiRNA targeting viral mRNA sequences encoding two gene silencing suppressors, P69 of TYMV and HCPro of turnip mosaic virus (TuMV). Transgenic Arabidopsis plants expressing amiR159-P69 and amiR159-HC-Pro were specifically resistant to TYMV and TuMV, respectively while transgenic plants that express both amiRs are resistant to both viruses (Niu Nat Biotech 2006) [106]. Similarly expression of amiR159-TuCP targeting coat protein sequences of TuMV also confers specific virus resistance. Significantly, the resistance trait is maintained at temperatures that 
compromises small interfering RNA-mediated gene silencing.

Thus amiRNA-mediated approach provides a powerful tool to study gene function in a gene family with multiple members. It also has broad applicability in producing virus resistance plants. This technique can also be employed for producing plants tolerant to different pathogens or abiotic stresses.

\section{CONCLUSIONS}

The diversity and complexity of plant function and architecture a propos with the surrounding environment involves precisely regulated and integrated action of several genes. Like transcriptional factors, miRNAs act as rheostats of gene expression. The versatility of these molecules is highlighted by their numerous and expanding roles in regulation of gene activity in nearly every cellular process. However, there is still a lot of ambiguity not only on the miRNA regulatory networks but also on the mechanisms of origin and regulation of a miRNA expression. Improvement in technologies to dissect the genome will enable a clear picture on the fine tuning of gene regulatory processes. This will be greatly aided by the ability to employ miRNAs as tools to engineer specific pathways in crop plants.

\section{ACKNOWLEDGEMENT}

We acknowledge Prof Sudhir K. Sopory (ICGEB, New Delhi) for his inspiration on initiating the miRNA work.

\section{REFERENCES}

[1] Fire A, Xu S, Montgomery MK, Kostas SA, Driver SE, Mello CC. Potent and specific genetic interference by double-stranded RNA in Caenorhabditis elegans. Nature 1998; 391: 806-11.

[2] Hamilton AJ, Baulcombe DC. A species of small antisense RNA in posttranscriptional gene silencing in plants. Science 1999; 286: 950-2.

[3] Vance V, Vaucheret H. RNA silencing in plants--defense and counter defense. Science 2001; 292: 2277-80.

[4] Bernstein E, Caudy AA, Hammond SM, Hannon GJ. Role for a bidentate ribonuclease in the initiation step of RNA interference. Nature 2001; 409: 363-6.

[5] Elbashir SM, Lendeckel W, Tuschl T. RNA interference is mediated by 21- and 22-nucleotide RNAs. Genes Dev 2001; 15: 188200.

[6] Hammond SM. Dicing and slicing: the core machinery of the RNA interference pathway. FEBS Lett 2005, 579: 5822-9.

[7] Agrawal N, Dasaradhi PV, Mohmmed A, Malhotra P, Bhatnagar RK, Mukherjee SK. RNA interference: biology, mechanism, and applications. Microbiol Mol Biol Rev 2003; 67: 657-85.

[8] Lee RC, Ambros V. An extensive class of small RNAs in Caenorhabditis elegans. Science 2001; 294: 862-4.

[9] Reinhart BJ, Slack FJ, Basson M, et al. The 21-nucleotide let-7 RNA regulates developmental timing in Caenorhabditis elegans. Nature 2000; 403: 901-6.

[10] Pasquinelli AE, Reinhart BJ, Slack F, et al. Conservation of the sequence and temporal expression of let-7 heterochronic regulatory RNA. Nature 2000; 408: 86-9.

[11] Griffiths-Jones S, Grocock RJ, Dongen SV, Bateman A, Enright AJ. miRBase: micro sequence, targets and gene nomenclature. Nuc Acids Res 2006; 34: 140-4.

[12] Llave C, Xie Z, Kasschau KD, Carrington JC. Cleavage of Scarecrow-like mRNA targets directed by a class of Arabidopsis miRNA. Science 2002; 297: 2053-6.

[13] Reinhart BJ, Weinstein EG, Rhoades MW, Bartel B, Bartel DP. MicroRNAs in plants. Genes Dev 2002; 16: 1616-26.

[14] Park W, Li J, Song R, Messing J, Chen X. CARPEL FACTORY, a Dicer homolog, and HEN1, a novel protein, act in microRNA metabolism in Arabidopsis thaliana. Curr Biol 2002; 12:1484-95.
[15] Bonnet E, Wuyts J, Rouze P, Van de Peer Y. Detection of 91 potential conserved plant microRNAs in Arabidopsis thaliana and Oryza sativa identifies important target genes. Proc Natl Acad Sci U S A. 2004; 101: 11511-6.

[16] Wang XJ, Reyes JL, Chua NH, Gaasterland T. Prediction and identification of Arabidopsis thaliana microRNAs and their mRNA targets. Genome Biol 2004a; 5: R65.

[17] Wang JF, Zhou H, Chen YQ, Luo QJ, Qu LH. Identification of 20 microRNAs from Oryza sativa. Nucleic Acids Res 2004b; 32: 1688-95.

[18] Bartel DP. MicroRNAs: genomics, biogenesis, mechanism, and function. Cell 2004; 116: 281-97.

[19] Palatnik JF, Wollmann H, Schommer C, et al. Sequence and Expression Differences Underlie Functional Specialization of Arabidopsis MicroRNAs miR159 and miR319. Dev Cell 2007; 13: 11525.

[20] Floyd SK, Bowman JL. Gene regulation: ancient microRNA target sequences in plants. Nature 2004; 428: 485-6

[21] Molnár A, Schwach F, Studholme DJ, Thuenemann EC, Baulcombe DC. miRNAs control gene expression in the single-cell alga Chlamydomonas reinhardtii. Nature 2007; 447: 1126-9.

[22] Barrangou R, Fremaux C, Deveau H, et al. CRISPR provides acquired resistance against viruses in prokaryotes. Science 2007; 315 : 1709-12.

[23] Palatnik JF, Allen E, Wu X, et al. Control of leaf morphogenesis by microRNAs. Nature 2003; 425: 257-63.

[24] Sunkar R, Zhu JK. Novel and stress-regulated microRNAs and other small RNAs from Arabidopsis. Plant Cell 2004; 16: 2001-19.

[25] Jones-Rhoades MW, Bartel DP. Computational identification of plant microRNAs and their targets, including a stress-induced miRNA. Mol Cell 2004; 14: 787-99.

[26] Adai A, Johnson C, Mlotshwa S, et al. Computational prediction of miRNAs in Arabidopsis thaliana. Genome Res 2005; 15: 78-91.

[27] Dezulian T, Remmert M, Palatnik JF, Weigel D, Huson DH. Identification of plant microRNA homologs. Bioinformatics 2006; 35960.

[28] Zhang B, Pan X, Anderson TA. Identification of 188 conserved maize microRNAs and their targets. FEBS Lett 2006; 580: 3753 62.

[29] Mica E, Gianfranceschi L, Pè ME. Characterization of five microRNA families in maize. J Exp Bot 2006; 57: 2601-12.

[30] Zhang BH, Pan XP, Wang QL, Cobb GP, Anderson TA. Identification and characterization of new plant microRNAs using EST analysis. Cell Res 2005; 15: 336-60.

[31] Lu S, Sun YH, Shi R, Clark C, Li L, Chiang VL. Novel and mechanical stress-responsive MicroRNAs in Populus trichocarpa that are absent from Arabidopsis. Plant Cell 2005; 17: 2186-203.

[32] Xie FL, Huang SQ, Guo K, et al. Computational identification of novel microRNAs and targets in Brassica napus. FEBS Lett 2007; 581: 1464-74.

[33] Yao Y, Guo G, Ni Z, et al. Cloning and characterization of microRNAs from wheat (Triticum aestivum L.). Genome Biol 2007; 8: R96.

[34] Pilcher RL, Moxon S, Pakseresht N, et al. Identification of novel small RNAs in tomato (Solanum lycopersicum). Planta 2007; 226: 709-17.

[35] Zhang B, Wang Q, Wang K, et al. Identification of cotton microRNAs and their targets. Gene 2007; 397: 26-37.

[36] Allen E, Xie Z, Gustafson AM, Sung GH, Spatafora JW, Carrington JC. Evolution of microRNA genes by inverted duplication of target gene sequences in Arabidopsis thaliana. Nat Genet 2004; 36: 1282-90.

[37] Fahlgren N, Howell MD, Kasschau KD, et al. High-Throughput Sequencing of Arabidopsis microRNAs: Evidence for Frequent Birth and Death of MIRNA Genes. PLoS ONE 2007; 2: e219.

[38] Kim VN. MicroRNA biogenesis: coordinated cropping and dicing. Nat Rev Mol Cell Biol 2005; 6: 376-85.

[39] Yi R, Qin Y, Macara IG, Cullen BR. Exportin-5 mediates the nuclear export of pre-microRNAs and short hairpin RNAs. Genes Dev 2003; 17: 3011-6.

[40] Lund E, Guttinger S, Calado A, Dahlberg JE, Kutay U. Nuclear export of microRNA precursors. Science 2004; 303: 95-8.

[41] Bollman KM, Aukerman MJ, Park MY, Hunter C, Berardini TZ, Poethig RS. HASTY, the Arabidopsis ortholog of exportin 5/MSN5, regulates phase change and morphogenesis. Development 2003; 130: 1493-1504. 
[42] Ruby JG, Calvin HJ, Bartel DP. Intronic microRNA precursors that bypass Drosha processing. Nature 2007; 448: 83-6.

[43] Okamura K, Hagen JW, Duan H, Tyler DM, Lai EC. The mirtron pathway generates microRNA-class regulatory RNAs in Drosophila. Cell 2007; 130: 89-100.

[44] Fagard M, Boutet S, Morel JB, Bellini C, Vaucheret. AGO1, QDE2 , and RDE-1 are related proteins required for post-transcriptional gene silencing in plants, quelling in fungi and RNA interference in animals. Proc Natl Acad Sci USA 2000; 97: 11650-4.

[45] Mourrain P, Beclin C, Vaucheret H. Are gene silencing mutants good tools for reliable transgene expression or reliable silencing of endogenous genes in plants? Genet Eng (N Y) 2000; 22: 155-70.

[46] Dalmay T, Horsefield R, Braunstein TH, Baulcombe DC. SDE3 encodes an RNA helicase required for post-transcriptional gene silencing in Arabidopsis. EMBO J 2001; 20: 2069-78.

[47] Lee YS, Nakahara K, Pham JW, et al. Distinct roles for Drosophila Dicer-1 and Dicer-2 in the siRNA/miRNA silencing pathway. Cell 2004; 117: 69-81.

[48] Ketting RF, Fischer SE, Bernstein E, Sijen T, Hannon GJ, Plasterk RH. Dicer functions in RNA interference and in synthesis of small RNA involved in developmental timing in C. elegans. Genes Dev 2001; 15: 2654-9.

[49] Finnegan EJ, Margis R, Waterhouse PM. Posttranscriptional gene silencing is not compromised in the Arabidopsis CARPEL FACTORY (DICER-LIKE1) mutant, a homolog of Dicer-1 from Drosophila. Curr Biol 2003; 13: 236-40.

[50] Xie Z, Johansen LK, Gustafson AM, et al. Genetic and functional diversification of small RNA pathways in plants PLoS Biol 2004; 2: E104.

[51] Jacobsen SE, Running MP, Meyerowitz EM. Disruption of an RNA helicase/RNAse III gene in Arabidopsis causes unregulated cell division in floral meristems. Development 1999; 126: 5231-43.

[52] Boutet S, Vazquez F, Liu J, Beclin C, Fagard M, Gratias A, Morel JB, Crete P, Chen X, Vaucheret H. Arabidopsis HEN1: a genetic link between endogenous miRNA controlling development and siRNA controlling transgene silencing and virus resistance. Curr Biol 2003; 13: 843-8.

[53] Suzuki M, Takahashi T, Komeda Y. Formation of Corymb-like inflorescences due to delay in bolting and flower development in the corymbosa2 mutant of Arabidopsis. Plant Cell Physiol 2002; 43: 298-306.

[54] Chen X. MicroRNA biogenesis and function in plants. FEBS Lett 2005; 579: 5923-31.

[55] Park MY, Wu G, Gonzalez-Sulser A, Vaucheret H, Poethig RS. Nuclear processing and export of microRNAs in Arabidopsis. Proc Natl Acad Sci USA 2005; 102: 3691-6.

[56] Han MH, Goud S, Song L, Fedoroff N. The Arabidopsis doublestranded RNA-binding protein HYL1 plays a role in microRNAmediated gene regulation. Proc Natl Acad Sci USA 2004; 101: 1093-8.

[57] Lu C, Fedoroff N. A mutation in the Arabidopsis HYL1 gene encoding a dsRNA binding protein affects responses to abscisic acid, auxin and cytokinin. Plant Cell 2000, 2: 2351-66.

[58] Vazquez F, Vaucheret H, Rajagopalan R, et al. Endogenous transacting siRNAs regulate the accumulation of Arabidopsis mRNAs. Mol Cell 2004; 16: 69-79.

[59] Yang L, Liu Z, Lu F, Dong A, Huang H. SERRATE is a novel nuclear regulator in primary microRNA processing in Arabidopsis. Plant J 2006; 47: 841-50.

[60] Bohmert K, Camus I, Bellini C, Bouchez D, Caboche M, Benning C. AGO1 defines a novel locus of Arabidopsis controlling leaf development. EMBO J 1998; 17: 170-80.

[61] Vaucheret H, Vazquez F, Crete P, Bartel DP. The action of ARGONAUTE1 in the miRNA pathway and its regulation by the miRNA pathway are crucial for plant development. Genes Dev 2004; 18: 1187-97.

[62] Kidner CA, Martienssen RA. The role of ARGONAUTE1 (AGO1) in meristem formation and identity. Dev Biol 2005; 280: 504-17.

[63] Cerutti L, Mian N, Bateman A. Domains in gene silencing and cell differentiation proteins: the novel PAZ domain and redefinition of the PIWI domain. Trends Biochem Sci 2000; 25: 481-2.

[64] Song JJ, Smith SK, Hannon GJ, Joshua-Tor L. Crystal structure of Argonaute and its implications for RISC slicer activity. Science 2004; 305: 1434-7.

[65] Zilberman D, Henikoff S. Silencing of transposons in plant genomes: kick them when they're down. Genome Biol 2004; 5: 249.
[66] Lippman Z, May B, Yordan C, Singer T, Martienssen R. Distinct mechanisms determine transposon inheritance and methylation via small interfering RNA and histone modification. PLoS Biol 2003; 1: E67.

[67] Mallory AC, Reinhart BJ, Jones-Rhoades MW, et al. MicroRNA control of PHABULOSA in leaf development: importance of pairing to the microRNA 5' region. EMBO J 2004; 23: 3356-64.

[68] Rhoades MW, Reinhart BJ, Lim LP, Burge CB, Bartel B, Bartel DP. Prediction of plant microRNA targets. Cell 2002; 110: 513-20.

[69] Mallory AC, Dugas DV, Bartel DP, Bartel B. MicroRNA regulation of NAC-domain targets is required for proper formation and separation of adjacent embryonic, vegetative, and floral organs. Curr Biol 2004; 14: 1035-46.

[70] Zhong R, Ye ZH. Amphivasal vascular bundle 1, a gain-of-function mutation of the IFL1/REV gene, is associated with alterations in the polarity of leaves, stems and carpels. Plant Cell Physiol 2004; 45: 369-85.

[71] Laufs P, Peaucelle A, Morin H, Traas J. MicroRNA regulation of the CUC genes is required for boundary size control in Arabidopsis meristems. Development 2004; 131: 4311-22.

[72] Kim J, Jung JH, Reyes JL, et al. microRNA-directed cleavage of ATHB15 mRNA regulates vascular development in Arabidopsis inflorescence stems. Plant J 2005; 42: 84-94.

[73] Ori N, Cohen AR, Etzioni A, et al. Regulation of LANCEOLATE by miR319 is required for compound-leaf development in tomato. Nat Genet 2007; 39: 787-91.

[74] Bowman, JL. Class III HD-Zip gene regulation, the golden fleece of ARGONAUTE activity? Bioessay 2004; 26:938-42.

[75] Juarez MT, Kui JS, Thomas J, Heller BA, Timmermans MC. microRNA-mediated repression of rolled leaf1 specifies maize leaf polarity. Nature 2004; 428: 84-8.

[76] Nath U, Crawford BC, Carpenter R, Coen E. Genetic control of surface curvature. Science 2003; 299: 1404-7.

[77] Aida M, Ishida T, Tasaka M. Shoot apical meristem and cotyledon formation during Arabidopsis embryogenesis: interaction among the CUP-SHAPED COTYLEDON and SHOOT MERISTEMLESS genes. Development 1999; 126: 1563-70.

[78] Riechmann JL, Heard J, Martin G, et al. Arabidopsis transcription factors: genome-wide comparative analysis among eukaryotes. Science 2000; 290: 2105-10.

[79] Hibara K, Karim MR, Takada S, Taoka K, Furutani M, Aida M, Tasaka M. Arabidopsis CUP-SHAPED COTYLEDON3 regulates postembryonic shoot meristem and organ boundary formation. Plant Cell 2006; 18: 2946-57.

[80] Achard P, Herr A, Baulcombe DC, Harberd NP. Modulation of floral development by a gibberellin-regulated microRNA. Development 2004; 131: 3357-65.

[81] Lauter N, Kampani A, Carlson S, Goebel M, Moose SP. microRNA172 down-regulates glossy15 to promote vegetative phase change in maize. Proc Natl Acad Sci USA. 2005; 102: 9412-7.

[82] Aukerman MJ, Sakai H. Regulation of flowering time and floral organ identity by a MicroRNA and its APETALA2-like target genes. Plant Cell 2003; 15: 2730-41.

[83] Chen X. A microRNA as a translational repressor of APETALA2 in Arabidopsis flower development. Science 2004; 303: 2022-5.

[84] Wu G, Poethig RS. Temporal regulation of shoot development in Arabidopsis thaliana by miR156 and its target SPL3. Development 2006; 133: 3539-47.

[85] Guo HS, Xie Q, Fei JF, Chua NH. MicroRNA directs mRNA cleavage of the transcription factor NAC1 to down regulate auxin signals for arabidopsis lateral root development. Plant Cell 2005; 17: $1376-86$

[86] Xie Q, Frugis G, Colgan D, Chua NH. Arabidopsis NAC1 transduces auxin signal downstream of TIR1 to promote lateral root development. Genes Dev 2000; 14: 3024-36.

[87] Ohashi-Ito K, Fukuda H. HD-zip III homeobox genes that include a novel member, ZeHB-13 (Zinnia)/ATHB-15 (Arabidopsis) are involved in procambium and xylem cell differentiation. Plant Cell Physiol 2003; 44: 1350-8.

[88] Sorin C, Bussell JD, Camus I, et al. Auxin and light control of adventitious rooting in Arabidopsis require ARGONAUTE1. Plant Cell 2005; 17: 1343-59.

[89] Mallory AC, Bartel DP, Bartel B. MicroRNA-directed regulation of Arabidopsis AUXIN RESPONSE FACTOR17 is essential for proper development and modulates expression of early auxin response genes. Plant Cell 2005; 17: 1360-75. 
[90] Hagen G, Guilfoyle T. Auxin-responsive gene expression: genes, promoters and regulatory factors. Plant Mol Biol 2002; 49: 373-85.

[91] Weijers D, Jurgens G. Funneling auxin action: specificity in signal transduction. Curr Opin Plant Biol 2004; 7: 687-93.

[92] Gocal GF, King RW, Blundell CA, Schwartz OM, Andersen CH, Weigel D. Evolution of floral meristem identity genes. Analysis of Lolium temulentum genes related to APETALA1 and LEAFY of Arabidopsis. Plant Physiol 2001; 125: 1788-801.

[93] Kaneko M, Inukai Y, Ueguchi-Tanaka M, et al. Loss-of-function mutations of the rice GAMYB gene impair alpha-amylase expression in aleurone and flower development. Plant Cell 2004; 16: 3344.

[94] Chiou TJ. The role of microRNAs in sensing nutrient stress. Plant Cell Environ 2007; 30: 323-32.

[95] Zhao B, Liang R, Ge L, et al. Identification of drought-induced microRNAs in rice. Biochem Biophys Res Commun 2007; 354: 585-90.

[96] Zhou X, Wang G, Zhang W. UV-B responsive microRNA genes in Arabidopsis thaliana. Mol Syst Biol 2007; 3: 103.

[97] Reyes JL, Chua NH. ABA induction of miR159 controls transcript levels of two MYB factors during Arabidopsis seed germination. Plant J 2007; 49: 592-606.

[98] Gurr SJ, Rushton PJ. Engineering plants with increased disease resistance: how are we going to express it? Trends Biotech 2005; 23: 283-90.
[99] Chapman EJ, Prokhnevsky AI, Gopinath K, Dolja VV, Carrington JC. Viral RNA silencing suppressors inhibit the microRNA pathway at an intermediate step. Genes Dev 2004; 18: 1179-86.

[100] Kasschau KD, Xie Z, Allen E, et al. P1/HC-Pro, a viral suppressor of RNA silencing, interferes with Arabidopsis development and miRNA function extent of virus invasion. RNA silencing involves recognition and processing of double-stranded RNA. Dev Cell 2003; 4: 205-17.

[101] Chen CZ, Li L, Lodish HF, Bartel DP. MicroRNAs modulate hematopoietic lineage differentiation. Science 2004; 303: 83-86.

[102] Xie Z, Kasschau KD, Carrington JC. Negative feedback regulation of Dicer-Like1 in Arabidopsis by microRNA-guided mRNA degradation. Curr Biol 2003; 13: 784-9.

[103] Allen E, Xie Z, Gustafson AM, Carrington JC. microRNA-directed phasing during trans-acting siRNA biogenesis in plants. Cell 2005; 121: 207-21.

[104] Alvarez JP, Pekker I, Goldshmidt A, Blum E, Amsellem Z, Eshed Y. Endogenous and synthetic microRNAs stimulate simultaneous, efficient, and localized regulation of multiple targets in diverse species. Plant Cell 2006; 18: 1134-51.

[105] Schwab R, Ossowski S, Riester M, Warthmann N, Weigel D. Highly specific gene silencing by artificial microRNAs in Arabidopsis. Plant Cell 2006; 18: 1121-33.

[106] Niu QW, Lin SS, Reyes JL, et al. Expression of artificial microRNAs in transgenic Arabidopsis thaliana confers virus resistance. Nat Biotech 2006; 24: 1420-8. 